Check for updates

Cite this: RSC Adv., 2018, 8, 22193

Received 16th April 2018 Accepted 4th June 2018

DOI: $10.1039 / c 8 r a 03245 a$

rsc.li/rsc-advances

\section{Preparation of $\mathrm{Co}-\mathrm{N}$ carbon nanosheet oxygen electrode catalyst by controlled crystallization of cobalt salt precursors for all-solid-state Al-air battery $\dagger$}

\author{
Jianhua Shen, (D) a Lu Meng, ${ }^{a}$ Yanyan Liu, ${ }^{a}$ Cheng Chen, (D) ${ }^{b}$ Yihua Zhu (D) *a \\ and Chunzhong $\mathrm{Li}$ (D)
}

Production of bifunctional catalysts for catalyzing both the oxygen reduction reaction (ORR) and oxygen evolution reaction (OER) is highly advisable but challenging with respect to the applications of these catalysts in renewable energy conversion and storage technologies. Herein, we prepared highly reactive and stable cobalt-embedded nitrogen-rich carbon nanosheets (Co-N/CNs). Based on density functional theory (DFT) calculations and experiments, the as-prepared Co-N/CNs showed outstanding catalytic activities toward both OER and ORR. The optimized Co-N/CNs-800 catalyst revealed outstanding bifunctional catalytic activities for both ORR and OER with high catalytic efficiency and long-term durability, which were even comparable with those of the state-of-the-art $\mathrm{Pt} / \mathrm{C}$ and $\mathrm{RuO}_{2}$ catalysts. Furthermore, we observed that different cobalt salt precursors affected the size of Co nanoparticles, and both ORR and OER catalytic activities displayed completely consistent variations (sulfate < acetate < chloride < nitrate). An all-solid-state Al-air battery device comprising this hybrid catalyst showed superior performance when compared with the device containing the $\mathrm{Pt} / \mathrm{C}$ catalyst.

\section{Introduction}

The continuous depletion of traditional fossil fuels and the associated environmental pollution have increased the demand for clean and sustainable energy sources such as rechargeable metal-air batteries, fuel cells and water-splitting devices..$^{1-3}$ These new energy conversion and storage technologies, which are driven by the oxygen reduction reaction (ORR) and oxygen evolution reaction (OER) as the crucial electrode processes, have been universally studied and developed because of their high energy densities. ${ }^{4}$ Currently, platinum-group-based catalysts are considered to be the best electrocatalysts for ORR or OER, but they are expensive and scarce largely due to their limited largescale applications. ${ }^{5}$ In addition, it is difficult for the same catalyst to synchronously accelerate ORR/OER activities, which is highly desirable yet a great challenge. 6,7

In the past decades, some alternative materials have been developed, and they exhibit bifunctional catalytic activities

${ }^{a}$ Key Laboratory for Ultrafine Materials of Ministry of Education, School of Materials Science and Engineering, East China University of Science and Technology, Shanghai 200237, P. R. China. E-mail: yhzhu@ecust.edu.cn; czli@ecust.edu.cn; Tel: +8602164252022; +860216425094

${ }^{b}$ School of Environmental and Materials Engineering, College of Engineering, Shanghai Polytechnic University, Shanghai 201209, China

$\dagger$ Electronic supplementary information (ESI) available. See DOI: $10.1039 / \mathrm{c} 8 \mathrm{ra} 03245 \mathrm{a}$ toward both OER and ORR. ${ }^{5-8}$ For example, carbon nanomaterials (especially $\mathrm{N}$-doped carbons with a break of electroneutrality and charge of local change density) have demonstrated promising OER and ORR activities and stabilities due to their low cost, adjustable surface chemistry and high electrical conductivity. ${ }^{9}$ Moreover, recent evidence indicates that the ORR active sites are carbon atoms next to pyridinic nitrogen with Lewis basicity in the N-doped nanocarbons. ${ }^{10}$ However, the density of $\mathrm{N}$-doped carbons is limited by the preparation method such as annealing of carbon nanomaterials in $\mathrm{NH}_{3}$ atmosphere and direct pyrolysis of $\mathrm{N}$-containing hydrocarbons or macromolecules. ${ }^{9}$ In particular, it is difficult to determine the suitable heat treatment temperature. Without optimization, unduly low or extremely high temperatures lead to low electronic conductivity or considerable loss of active $\mathrm{N}$ species, respectively. ${ }^{11}$ Hence, a substantial increase in the effective active sites in $\mathrm{N}$-doped nanocarbons remains challenging.

In this regard, recent studies have shown that Co-doping with transition metals and $\mathrm{N}$ carbons $(\mathrm{M}-\mathrm{N} / \mathrm{C})$ could further enhance the bifunctional electrocatalytic activity through the introduction of more active additives and their synergistic effects; ${ }^{12}$ among these catalysts, Co-N/C nanocomposites have been extensively studied as promising ORR catalysts owing to strong interactions between Co-embedded and $\mathrm{N}$-doped species in the carbon frameworks. ${ }^{8,13}$ Zou et al. reported cobalt- 
embedded nitrogen-rich CNTs via thermal treatment of $\mathrm{Co}^{2+}$ functionalized graphitic carbon nitride $\left(\mathrm{Co}^{2+}-g-\mathrm{C}_{3} \mathrm{~N}_{4}\right)$ at $700{ }^{\circ} \mathrm{C}$ in an $\mathrm{N}_{2}$ atmosphere. ${ }^{14}$ Due to the catalytic effect of cobalt ions, CNT-based materials are used to catalyse electrochemical reaction automatically. Through comparison with studies by Xie et al., the surface cobalt atoms in two-dimensional nanosheets exhibited higher intrinsic activities and stabilities than bulk materials. ${ }^{15}$ However, many problems still exist in the preparation and design of 2D nanomaterials with controlled mesopores and compositions.

Herein, we demonstrate an efficient method, wherein Coembedded N-rich carbon nanosheets (Co-N/CNs) (Fig. 1A) can be developed as highly active bifunctional electrocatalysts for OER and ORR under alkaline conditions. The synergistic effect between Co and N-doping leads to improved electrocatalytic performance, and the oxygen electrode activity parameter $\Delta E$ (the criteria for judging the overall catalytic activity of bifunctional electrocatalysts) value for the well-designed catalyst is $0.84 \mathrm{~V}$, which exceeds those of $\mathrm{Pt} / \mathrm{C}$ and $\mathrm{RuO}_{2}$ catalysts as well as those of most non-precious metal catalysts reported in previous literature studies. Density functional theory (DFT) was applied to study the effects of Co- and $\mathrm{N}$-doping in carbon nanosheets, and the activation energy of ORR decreased significantly on the

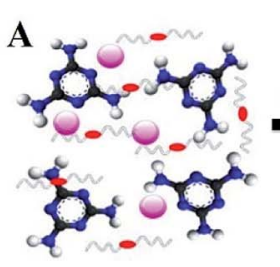

$\not 2-$ Melamine

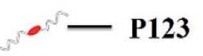

$\bigcirc-\mathrm{Co}^{2+}$
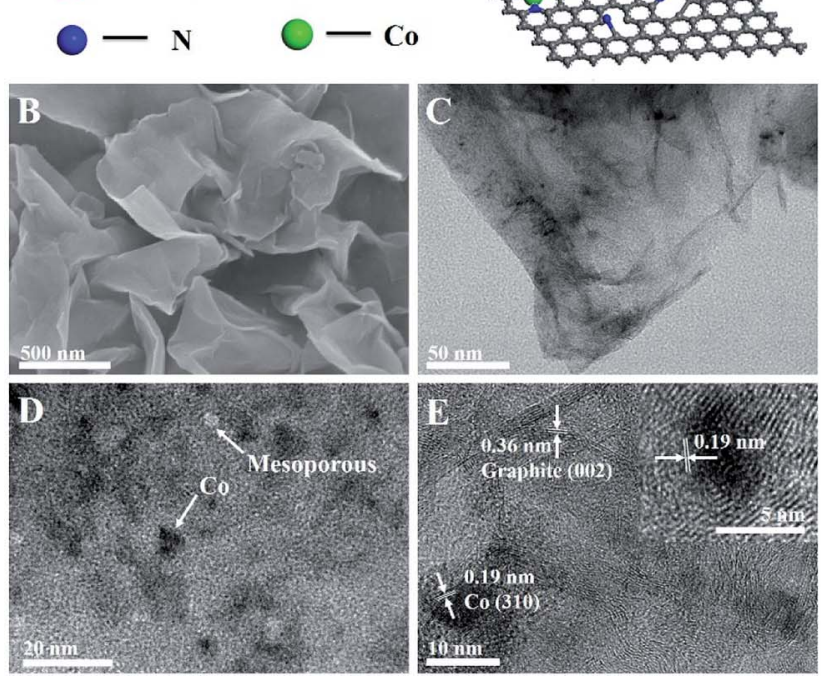

Fig. 1 (A) Schematic diagram of the fabrication of Co-N/CNs. (B) SEM image of Co-N/CNs-800 after acid treatment, typical graphene-like sheet morphology with no clear nanoparticles. (C) TEM image of Co$\mathrm{N} / \mathrm{CNs}-800$. (D and E) HRTEM images of Co-N/CNs-800. The inset of (E) is an individual Co nanoparticle embedded in carbon. surface of multi-doped carbon nanosheets, accounting for the enhanced catalytic performance. Interestingly, an all-solid-state Al-air battery was constructed using Co-N/CN electrodes, and it showed good electrochemical performance and high stability, which was superior to that of $\mathrm{Pt} / \mathrm{C}$ catalyst.

\section{Experimental section}

\section{Material synthesis}

In the typical procedure, melamine $(0.75 \mathrm{~g}), \mathrm{Co}\left(\mathrm{NO}_{3}\right)_{2} \cdot 6 \mathrm{H}_{2} \mathrm{O}$ (0.121 g), PEO-PPO-PEO (P123, $0.5 \mathrm{~g}$ ) and ultrapure water $(15 \mathrm{~mL})$ were stirred for about $2 \mathrm{~h}$ at room temperature. Then, the solution was dried at $80{ }^{\circ} \mathrm{C}$ to remove water. The dried precursor was placed in a crucible and heated to $500{ }^{\circ} \mathrm{C}$ to form $\mathrm{Co}^{2+}$-functionalized carbon nitride; subsequently, the mixture was heated to an appointed temperature $\left(700,800\right.$ and $\left.900{ }^{\circ} \mathrm{C}\right)$ at the rate of $3{ }^{\circ} \mathrm{C} \mathrm{min}^{-1}$ for $2 \mathrm{~h}$ in an $\mathrm{N}_{2}$ atmosphere. Unstable and inactive species were removed from the heat-treated samples via pre-leaching in $0.5 \mathrm{M} \mathrm{H}_{2} \mathrm{SO}_{4}$ at $80{ }^{\circ} \mathrm{C}$ for $24 \mathrm{~h}$. The products are referred to as Co-N/CNs- $X$ with $X$ being the annealing temperature.

\section{Fabrication of all-solid-state Al-air battery}

A home-made Al-air battery device was employed for battery performance and stability measurements. Alkaline polymer electrolyte films were prepared by the solution casting method. PVA $(2.0 \mathrm{~g})$ was dissolved in $20 \mathrm{~mL}$ water and stirred for one day. $\mathrm{KOH}$ (6.74 g) was dissolved in $20 \mathrm{~mL}$ water and stirred until it was completely dissolved. The two solutions were mixed together and stirred again for $25 \mathrm{~h}$. The mixed solutions were poured into Petri dishes and left to dry slowly at $25^{\circ} \mathrm{C}$ to form films. These films of about $3 \mathrm{~mm}$ thickness were placed in a dry environment with relative humidity of $\sim 24 \%$ for three months. A porous air cathode was prepared by casting a cathodic paste onto a Ni foam. A mixture composed of conductive material (70 $\mathrm{mg}$ of activated carbon and $10 \mathrm{mg}$ of ether black) and catalyst $(20 \mathrm{mg})$ was milled together with $8 \mathrm{mg}$ PVDF as the polymer binder. The solid blend was dispersed in NMP to form a viscous paste. PVDF could tightly bind electrode composites to the Ni foam at room temperature. The Ni foam was used as both mechanical support and current collector, and it was stuffed with the cathodic paste. A smooth surface was obtained by the cold press process to sufficiently contact with the gel electrolyte film. Micropores were formed due to the evaporation of the NMP solvent, through which air could penetrate into the porous cathode. A polished Al plate was used as the anode. As a reference material, $20 \mathrm{wt} \% \mathrm{Pt} / \mathrm{C}$ catalyst was prepared using the same procedure.

\section{Results and discussion}

Co-N/CNs were prepared by novel self-assembly and two-step thermal treatment, as shown schematically in Fig. 1A. During the synthesis process, the precursor was self-assembled and further heated at $500{ }^{\circ} \mathrm{C}$ in $\mathrm{N}_{2}$ atmosphere to polymerize and form $\mathrm{Co}^{2+}$-functionalized carbon nitride nanosheets, which was 
similar to the procedure given in the literature ${ }^{14}$ Furthermore, the prepared $\mathrm{Co}-\mathrm{N} / \mathrm{CN}$ catalysts were carbonized at high temperature, which reduced $\mathrm{Co}^{2+}$ to Co nanoparticles, thus forming carbon nanosheets. Finally, the resulting materials underwent acid treatment with $0.5 \mathrm{M} \mathrm{H}_{2} \mathrm{SO}_{4}$ for $12 \mathrm{~h}$ to remove any accessible Co species present. In addition, the effects of different carbonization temperatures $\left(700,800\right.$ and $\left.900{ }^{\circ} \mathrm{C}\right)$ and different $\mathrm{Co}^{2+}$ salt precursors were investigated.

In Fig. 1B, the scanning electron microscopy (SEM) image displays typical graphene-like sheet morphology in which no clear nanoparticles can be seen, due to the negligible size of cobalt nanoparticles (Co NPs). Transmission electron microscopy (TEM) images exhibit that the formed Co NPs are uniformly loaded on thin carbon sheets (Fig. 1C and D). The size distribution histogram demonstrates that these Co NPs have an average size of $5.6 \mathrm{~nm}$ with narrow distribution. After acid treatment and removal of Co NPs, we can observe the corresponding mesopores (Fig. S1†). Fig. 1E demonstrates the well-defined crystalline lattice spacings of 0.19 and $0.36 \mathrm{~nm}$, which match well with the (310) planes of the Co phase and (002) planes of the graphite phase, respectively. Notably, the Co NPs are surrounded by a few graphitic carbon layers despite acid washing, implying good electrochemical activity and stability for catalytic reactions. The presence of metallic Co and crystalline carbon in Co-N/CNs is affirmed by powder X-ray diffraction (XRD), as shown in Fig. S2. $\uparrow$ X-Ray Photoelectron Spectroscopy (XPS) and Thermogravimetric Analysis (TGA) (Fig. S3 and S4 $\dagger$ ) reveal that the $\mathrm{Co} / \mathrm{C}$ atomic ratio and $\mathrm{wt} \%$ of Co in Co-N/CNs-800 are $2: 100$ and $8.84 \%$, respectively.

The $\mathrm{N}$ 1s XPS spectrum of Co-N/CNs-800 (Fig. 2A) further displays the presence of two types of $\mathrm{N}$ species, which can be ascribed to pyridinic $\left(\mathrm{N}_{\mathrm{p}}\right)$ and quaternary $\left(\mathrm{N}_{\mathrm{q}}\right) \mathrm{N}$ atoms. Further quantitative analysis of the XPS result shows that the atomic
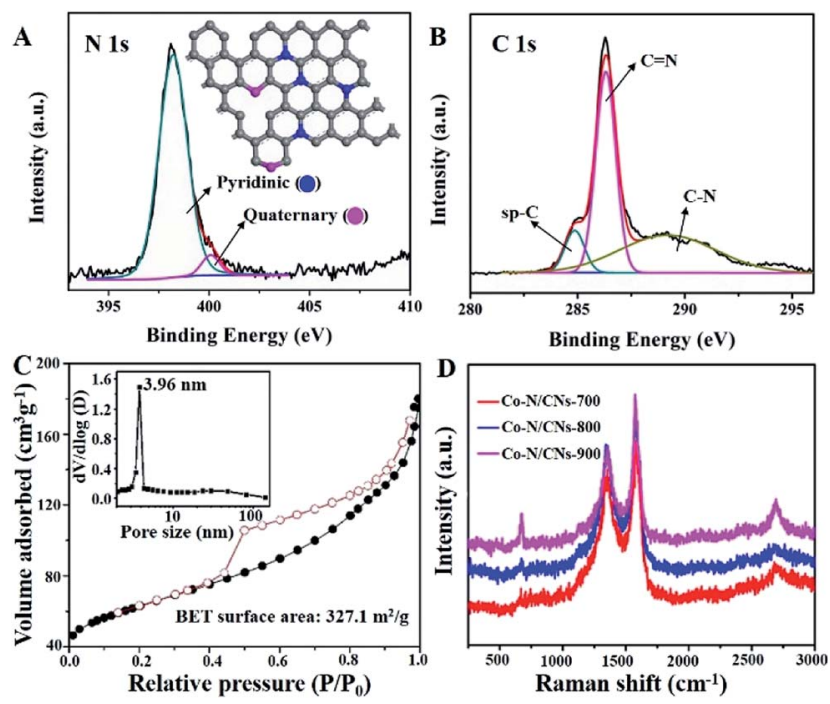

Fig. 2 (A) N 1s XPS spectrum of Co-N/CNs-800, the inset displays the two types of $\mathrm{N}$ dopants present in $\mathrm{Co}-\mathrm{N} / \mathrm{CNs}-800$ based on XPS results. (B) High-resolution spectrum of $C$ 1s. (C) $\mathrm{N}_{2}$ adsorption/ desorption isotherm of $\mathrm{Co}-\mathrm{N} / \mathrm{CNs}-800$ and the corresponding pore size distribution (the inset). (D) Raman spectra of Co-N/CNs. ratios of $\mathrm{N} / \mathrm{C}\left[\right.$ or $\left.\left(\mathrm{N}_{\mathrm{p}}+\mathrm{N}_{\mathrm{q}}\right) / \mathrm{C}\right], \mathrm{N}_{\mathrm{p}} / \mathrm{C}$ and $\mathrm{N}_{\mathrm{q}} / \mathrm{C}$ in Co-N/CNs-800 are $10.3: 100,9.3: 100$, and $1: 100$, respectively. Notably, $\mathrm{N}_{\mathrm{p}}$ and $\mathrm{N}_{\mathrm{q}}$ have been considered as electrochemically active sites in previous studies. The high-resolution spectrum of C 1s (Fig. 2B) can be deconvoluted to several single peaks corresponding to sp-C, $\mathrm{C}=\mathrm{N}, \mathrm{C}-\mathrm{O}, \mathrm{C}=\mathrm{O}$ and $\mathrm{C}-\mathrm{N}$, confirming the existence of heteroatoms in hybrids. ${ }^{16}$ The Co $2 \mathrm{p}_{3 / 2}$ and $2 \mathrm{p}_{1 / 2}$ highresolution spectra correspond to $\mathrm{Co}^{(0)}$ and $\mathrm{Co}-\mathrm{N}_{x}$ peaks (Fig. S5†) ${ }^{17}$ Moreover, the Co high-resolution spectra display no peaks consistent with the $\mathrm{Co}^{\delta}(\delta>2)$ species, which further indicates that Co NPs encapsulated in carbon layers are not sensitive to an aerobic atmosphere to be oxidized.

The $\mathrm{N}_{2}$ adsorption/desorption isotherm of Co-N/CNs-800 (Fig. 2C) demonstrates type-IV isotherm with a surface area of $327.1 \mathrm{~m}^{2} \mathrm{~g}^{-1}$. The mesoporous structure is observed at $4 \mathrm{~nm}$, which is demonstrated by the pore size distributions (the inset of Fig. 2C), and this result is shown in the TEM image in Fig. 1D. Raman measurements are conducted to demonstrate structural defects. In Fig. 2D, the D- and G-bands at approximately 1357 and $1577 \mathrm{~cm}^{-1}$, respectively, clearly demonstrate the existence of disordered and graphitic carbon..$^{18}$ Furthermore, the intensity ratio of D- and G-bands $\left(I_{\mathrm{D}} / I_{\mathrm{G}}\right)$ slightly decreases with an increase in the annealing temperature, and the values are 0.85 for Co-N/CNs-700, 0.80 for Co-N/CNs-800, and 0.65 for $\mathrm{Co}-\mathrm{N} /$ CNs-900, indicating that graphitization can be enhanced at higher temperatures.

The annealing temperature highly influences the electrocatalytic activities of these M-N/C catalysts, which has been demonstrated previously. ${ }^{19}$ Therefore, both ORR and OER activities of $\mathrm{Co}-\mathrm{N} / \mathrm{CN}$ catalysts prepared at different temperatures are studied in $\mathrm{O}_{2}$-saturated $0.1 \mathrm{M} \mathrm{KOH}$ solutions. Linear sweep voltammetry (LSV) curves indicate that the Co-N/CNs-800 catalyst has positive onset potential $(0.98 \mathrm{~V})$ and the highest diffusion-limited current density among the three Co-N/CNs catalysts (Fig. 3A); these values are fractionally lower than those of commercial Pt/C catalyst $(1.06 \mathrm{~V})$. The half-wave potential of Co-N/CNs-800 $(0.890 \mathrm{~V})$ is more positive than that of the $\mathrm{Pt} / \mathrm{C}$ catalyst $(0.877 \mathrm{~V})$. With respect to ORR activities, the prepared $\mathrm{Fe}-\mathrm{N} / \mathrm{CN}$ catalyst displays lower activity in terms of the onset potential $(0.987 \mathrm{~V})$ and half-wave potential $(0.845 \mathrm{~V})$ when compared with the synthesized catalysts (Fig. S6 $\dagger$ ). To further examine the ORR catalytic activities of Co-N/CNs-800 catalysts, LSVs using a rotating disk electrode (RDE) in $\mathrm{O}_{2}$-saturated $0.1 \mathrm{M}$ $\mathrm{KOH}$ at various rotating speeds are revealed in Fig. S7. $\dagger$ The voltammetric profiles of $\mathrm{Co}-\mathrm{N} / \mathrm{CNs}-800$ manifest a typical increase in current density with higher rotation rates (from 400 to $1600 \mathrm{rpm}$ ), and the average electron transfer number $(n)$ is 3.98 in the $K-L$ plots (Fig. S8 $\dagger$ ). High and steady electron transfer number values exhibit that these catalysts favour a fourelectron reduction process. ${ }^{20}$

In addition, the Co-N/CNs-800 catalyst also displayed the best OER activity in terms of overpotential $(\eta)$ at a current density of $10 \mathrm{~mA} \mathrm{~cm}^{-2}$, as shown in Fig. 3B. These results could be due to a balance of porosity, electrical conductivity, and type and density of active sites at the optimized temperature (800 $\left.{ }^{\circ} \mathrm{C}\right) .{ }^{21} \mathrm{Co}-\mathrm{N} / \mathrm{CNs}-700$ prepared at low temperature exhibited low electrical conductivity, which blocked the charge transfer. Co- 

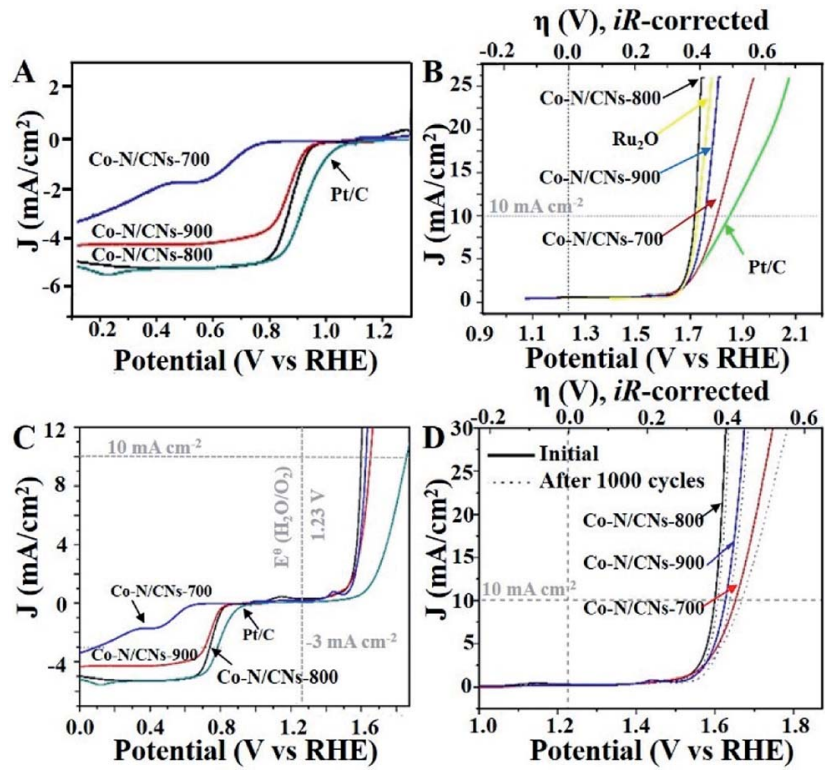

Fig. 3 (A) RDE LSV curves of different catalysts at a rotation rate of $1600 \mathrm{rpm}$ with a scan rate of $10 \mathrm{mV} \mathrm{s}^{-1}$. (B) Polarization curves of all catalysts. The ionic resistance $(\sim 45 \Omega)$ from the solution was determined via iR compensation test. (C) Oxygen electrode activities within the ORR and OER potential windows of various catalysts dispersed on the glass carbon electrode in $\mathrm{O}_{2}$-saturated $0.1 \mathrm{M} \mathrm{KOH}$. (D) OER linear sweep voltammograms of all $\mathrm{Co}-\mathrm{N} / \mathrm{CN}$ catalysts in $\mathrm{O}_{2}$-saturated $0.10 \mathrm{M} \mathrm{KOH}$ before and after 1000 cycles.

N/CNs-900 prepared at high temperature showed lack of catalytically active sites. In our case, Co-N/CNs-800 could obtain significant current density at a small $\eta$ of $\sim 0.39 \mathrm{~V}$, approaching the $\eta$ requirement for commercial $\mathrm{RuO}_{2}$ catalyst. The OER kinetics of the prepared catalysts were further probed through the Tafel slope. The resultant Tafel slopes were approximately

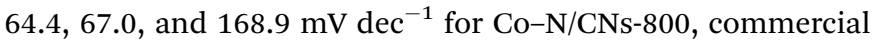
$\mathrm{RuO}_{2}$, and Pt/C, respectively (Fig. S9†). Notably, Co-N/CNs-800 exhibited the smallest Tafel slope and was therefore the most efficient OER catalyst among the studied catalysts, confirming superior intrinsic OER kinetics of this kind of Co-based material compared with that of the commercial $\mathrm{RuO}_{2}$ catalyst.

To better compare the bifunctional catalytic activities, it is a common method to calculate the oxygen electrode activity parameter $\Delta E\left(\Delta E=E_{\mathrm{J} 10 \text {,OER }}-E_{\mathrm{J}-3, \mathrm{ORR}}\right)$. As shown in Fig. 3C, Co-N/CNs-800 exhibited the smallest $\Delta E(0.84 \mathrm{~V})$, implying the best bifunctional catalytic activity and the highest potential for actual applications. In addition, compared to some reported bifunctional electrocatalysts (Table S1 $^{\text {) }}$, Co-N/CNs-800 exhibited high performance, showing great promise for use in rechargeable metal-air batteries. The stabilities of $\mathrm{Co}-\mathrm{N} / \mathrm{CN}$ catalysts were also studied by OER LSV measurements in $\mathrm{O}_{2}$ saturated $0.10 \mathrm{M} \mathrm{KOH}$ before and after 1000 cycles. The OER polarization curve of Co-N/CNs-800 displayed almost no change after 1000 cycles (Fig. 3D). On the contrary, no clear change was observed in the ORR current at Co-N/CNs-800. This indicated that the Co-N/CNs-800 electrode possessed higher ORR selectivity and greater tolerance to methanol crossover than the $\mathrm{Pt} / \mathrm{C}$ catalyst. Additionally, chronoamperometric durability tests for ORR are also shown in Fig. S10. $\uparrow$ The Pt/C catalyst displayed $13.2 \%$ decrease in activity after $10000 \mathrm{~s}$ at $-0.4 \mathrm{~V}$. In comparison, Co-N/CNs-800 retained a high relative current of $95.8 \%$ after $10000 \mathrm{~s}$, suggesting the increasing stability of active reaction sites on $\mathrm{Co}-\mathrm{N} / \mathrm{CNs}-800$ than on $\mathrm{Pt} / \mathrm{C}$ in alkaline solution.

Unlike previous discussions, additional studies were actualized to gain insights into the origin of the superior catalytic activity of Co-N/CNs-800 as well as their structure-catalytic activity relationships. This primarily included the synthesis of materials by self-assembly and pyrolysis of Co-N/CNs with different cobalt precursors (sulfate, acetate, chloride and nitrate), followed by investigation of their electrocatalytic performances. Fig. 4A shows the cyclic voltammograms (CV) of Co-N/CNs prepared using different cobalt precursors, and it displays a substantial reduction process. Apparently, Co-N/CNs (nitrate) revealed pronounced electrocatalytic ORR activity associated with a more positive ORR potential peak and higher current density value than the other samples. Additionally, the rotating disk electrode (RDE) LSV curves and polarization curves of Co-N/CNs with different cobalt precursors are also displayed in Fig. S11. $\dagger$ As the results were almost the same in both cases, we inferred that Co-N/CNs (nitrate) exhibited the best electrochemical catalytic performance. The comparison results are discussed in detail below.

As shown in Fig. 4B, both ORR and OER catalytic activities displayed consistent variations (sulfate $<$ acetate $<$ chloride $<$ nitrate). SEM images of different samples are shown in Fig. S12, $\uparrow$ and the most important point is that the corresponding particle sizes showed a constant increase with catalytic activity. Transition metal nanoparticles have been investigated for replacing noble metal-based catalysts, the size
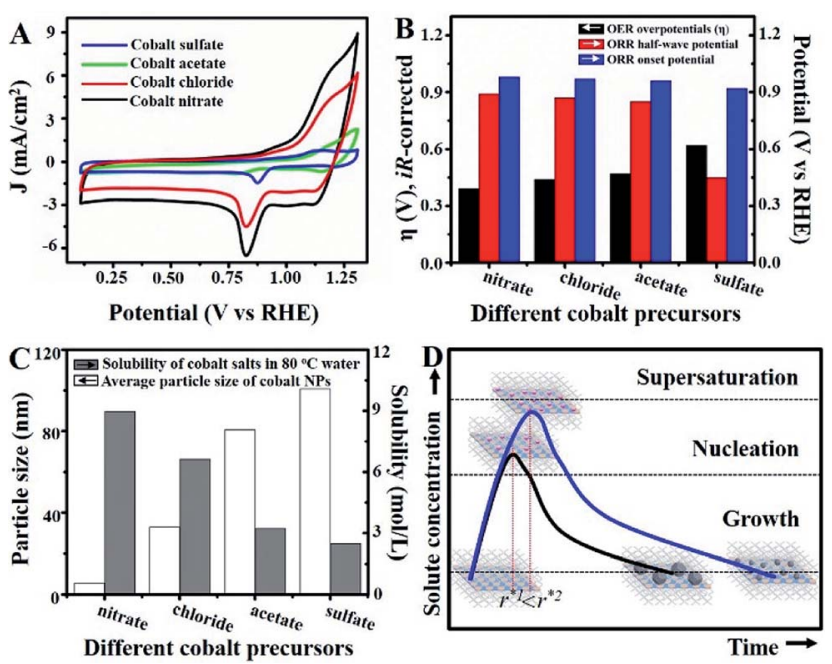

Fig. 4 (A) Cyclic voltammograms for $\mathrm{Co}-\mathrm{N} / \mathrm{CNs}$ with different cobalt precursors in $\mathrm{O}_{2}$-saturated $0.10 \mathrm{M} \mathrm{KOH}$ at scan rate of $50 \mathrm{mV} \mathrm{s}^{-1}$. (B) Histograms for OER and ORR electrocatalytic properties of Co-N/CNs with different cobalt precursors (sulfate, acetate, chloride and nitrate). (C) Histograms for the relationship between water solubility and nanoparticle size. (D) Schematic diagram of the self-assembly process. 
of which directly affects catalytic activity. ${ }^{22}$ Sa et al. developed the general "silica-protective-layer-assisted" approach, and it can preferentially generate small nanoparticles with high catalytic activity sites. ${ }^{23}$ However, in this study, we accidentally discovered the novel result that the size of transition metal nanoparticles can also be controlled by different precursors (Fig. 4C). The simple solubilities of these cobalt salts were inversely related to the nanoparticle size (specific values in Table S2 $\dagger$ ). In the schematic diagram of Fig. 4D, the model curves of different solubility precursors (1-low and 2-high solubility) and reaction time display the self-assembly processes including solvent evaporation, nucleation and growth. As shown in Fig. 1, the block copolymer P123 and carbon source were self-assembled to lamellar micelle structures, and $\mathrm{Co}^{2+}$ was adsorbed on the surfaces of these sheets. With volatilization of water, cobalt salts underwent nucleation and growth on these sheets. Furthermore, these cobalt salt crystals were reduced and coated with carbon after high-temperature calcination. Thus, the dimensions of these crystals directly affected the size of final Co nanoparticles in carbon nanosheets. As shown in Fig. S13, $\uparrow r^{*}$ is the critical nuclei size: ${ }^{24}$

$$
r^{*}=\frac{2 V \gamma}{3 k_{\mathrm{B}} T \ln (S)}
$$

here, $V$ is the molecular volume of the precipitated species, $k_{\mathrm{B}}$ is the Boltzmann constant, $S$ is the saturation ratio, and $\gamma$ is the surface free energy per unit surface area. As shown in the result, $r^{* 1}<r^{* 2}$; the corresponding final nanoparticles also had the same order.

To understand the nature of the high ORR and OER reactivities of Co-N/CNs, density functional theory (DFT) calculations are revealed based on the four-electron pathway mechanism for both ORR and OER in the ESI. $\dagger$ For comparison, both Co-N/CNs and Co nanoparticles were considered, as shown in Fig. 5A and S14. $\dagger$ During the process of ORR, it was very important to understand the adsorption abilities of the surfaces of catalysts. As shown in Fig. 5B, when $\mathrm{O}_{2}$ was adsorbed on $\mathrm{CoN}_{3}$ and $\mathrm{Co}_{6}$ sites, an interaction occurred below $-6.5 \mathrm{eV}$ between the $\mathrm{O} 2 \mathrm{~s} 2 \mathrm{p}$-band and Co $3 \mathrm{~d} 4 \mathrm{~s}$-band near the Fermi level, and the $\mathrm{O}$ 2s2p-band was also broadened near the Fermi level. When $\mathrm{O}_{2}$ was adsorbed on the $\mathrm{Co}_{6}$ site, the interaction between the adsorbed $\mathrm{O}_{2}$ and corresponding atoms was weaker than that at the $\mathrm{CoN}_{3}$ site. The free energy diagrams of ORR substeps on active $\mathrm{CoN}_{3}$ sites are presented in Fig. 5C. Desorption of $\mathrm{OH}^{-}$was the last step that became gradient as the potential decreased; this was regarded to be the rate determining step. The rate determining step for the $\mathrm{Co}_{6}$ site was revealed to be the transformation of $\mathrm{O}_{2}$ to $\mathrm{OOH}^{*}$ (Fig. 5D). For ORR on $\mathrm{CoN}_{3}$ sites, ORR substeps were all downhill when the electrode potential was $0 \mathrm{~V}$, corresponding to a short circuit condition of fuel cells. As the electrode potential increased to $1.23 \mathrm{~V}$, the reaction steps were all uphill, corresponding to an open circuit condition of fuel cells. Desorption of $\mathrm{OH}^{*}$ as $\mathrm{OH}^{-}$ became uphill, whereas other subreactions remained downhill at $U=1.09 \mathrm{~V}$; thus, the desorption of $\mathrm{OH}^{*}$ as $\mathrm{OH}^{-}$was the rate determining step in ORR.
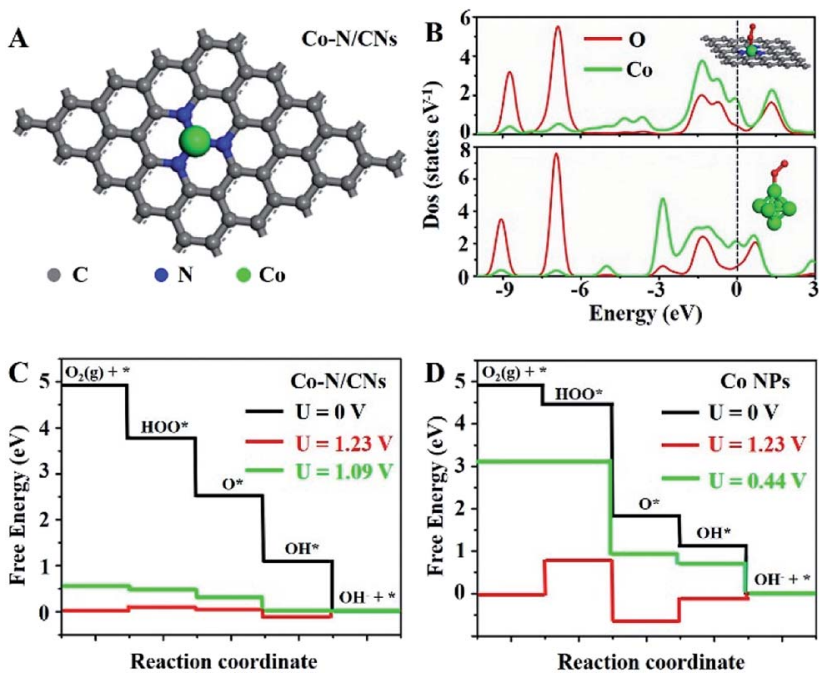

Fig. 5 DFT calculations of the ORR activities of $\mathrm{Co}-\mathrm{N} / \mathrm{CNs}$ and $\mathrm{Co}$ nanoparticles. (A) Schematic model of Co-N/CNs, Co (green), N (blue), and C (gray). (B) Partial electronic density of states (PDOS) of adsorbed oxygen on Co-N/CNs and Co nanoparticles (inset is the model of $\mathrm{CO}_{6}$ cluster). The Fermi level is set at $\mathrm{O} \mathrm{eV}$. Calculated free energy diagrams of ORR at $\mathrm{pH}=13$ for (C) $\mathrm{Co}-\mathrm{N} / \mathrm{CNs}$ with $\mathrm{Co}-\mathrm{N}_{3}$ site in a periodic $5 \times 5 \times 1$ graphene and (D) Co nanoparticles.

On the basis of the promising electrochemical activity of the as-obtained $\mathrm{Co}-\mathrm{N} / \mathrm{CN}$ catalyst, the $\mathrm{Co}-\mathrm{N} / \mathrm{CNs}-800$ electrocatalyst was further integrated into an all-solid-state $\mathrm{Al}$-air battery (Fig. 6A). As shown in Fig. 6B, the maximum power density of the Al-air battery using Co-N/CNs-800 catalyst was as high as $41.5 \mathrm{~mW} \mathrm{~cm}^{-2}$, and it showed similar performance when compared to $\mathrm{Pt} / \mathrm{C}$ catalyst $\left(43.1 \mathrm{~mW} \mathrm{~cm}^{-2}\right.$ ). Moreover, the discharging performances suggested that there was no clear voltage change before the first 8 hours (Fig. 6C), indicating

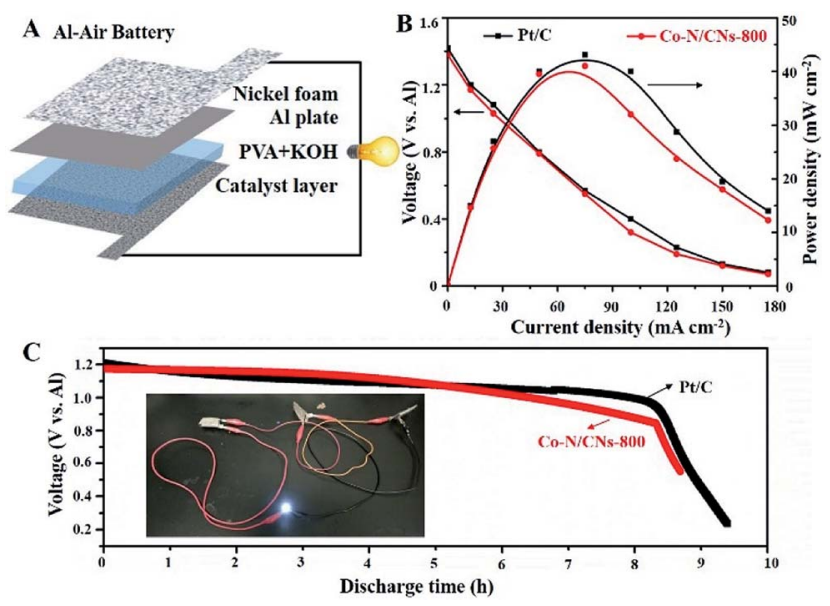

Fig. 6 Electrochemical performances of $\mathrm{Co}-\mathrm{N} / \mathrm{CNs}-800$ and $\mathrm{Pt} / \mathrm{C}$ in a homemade all-solid-state Al-air battery device. (A) Schematic of the all-solid-state Al-air battery. (B) Discharge polarization curves and corresponding power density plots. (C) Discharge curves for all-solidstate $\mathrm{Al}-$ air battery with electrocatalysts of $\mathrm{Co}-\mathrm{N} / \mathrm{CNs}-800$ and $\mathrm{Pt} / \mathrm{C}$ at a constant discharge current density of $12.5 \mathrm{~mA} \mathrm{~cm}^{-2}$; inset, white LED lit up by three prepared devices in series. 
excellent stability of the Co-N/CNs-800 catalyst in Al-air batteries. The inset is an example that demonstrates the potential of our all-solid-state Al-air battery for practical applications. It can be clearly seen that after using three devices connected in series, a white (3.0 V) LED was lit up. These results revealed that the as-obtained $\mathrm{Co}-\mathrm{N} / \mathrm{CNs}-800$ catalyst has potential in the metal-air battery field..$^{25,26}$

\section{Conclusions}

In conclusion, the reaction pathway of ORR/OER has been explored through experimental electrochemical evaluation and theoretical calculations using unique Co NPs in N-doped carbon nanosheets via two-step solid-state thermal reaction approach. The optimized Co-N/CNs-800 catalyst revealed outstanding bifunctional catalytic activities toward both ORR and OER with high catalytic efficiency and long-term durability, which were comparable with those of the state-of-the-art Pt/C and $\mathrm{RuO}_{2}$ catalysts. The results based on the different solubilities of cobalt salt precursors revealed that cobalt nitrate was the best precursor due to the crystal growth law. In addition, the crucial role of atomically dispersed Co was further understood by DFT calculations. The as-prepared Co-N/CNs-800 catalyst also achieved superior performance as an air cathode for an allsolid-state Al-air battery device. This study will pave a new way for designing advanced electrochemical catalysts for new energy conversion systems.

\section{Conflicts of interest}

There are no conflicts to declare.

\section{Acknowledgements}

This work was supported by the National Natural Science Foundation of China (21776092, 21471056, 21676093, 91534202), the Basic Research Program of Shanghai (15JC1401300, 17JC1402300), the Shanghai Rising-Star Program (18QA1401500), the Social Development Program of Shanghai (17DZ1200900), Innovation Program of Shanghai Municipal Education Commission, and the Fundamental Research Funds for the Central Universities (222201718002).

\section{Notes and references}

1 J. Shen, Y. Zhu, H. Jiang and C. Li, Nano Today, 2016, 11, 483520.

2 S. Chu and A. Majumdar, Nature, 2012, 488, 294-303.

3 L. Han, S. Dong and E. Wang, Adv. Mater., 2016, 28, 92669291.

4 M. K. Debe, Nature, 2012, 486, 43-51.
5 P. Chen, T. Zhou, L. Xing, K. Xu, Y. Tong, H. Xie, L. Zhang, W. Yan, W. Chu, C. Wu and Y. Xie, Angew. Chem., Int. Ed., 2017, 56, 610-614.

6 Z. Li, M. Shao, Q. Yang, Y. Tang, M. Wei, D. G. Evans and X. Duan, Nano Energy, 2017, 37, 98-107.

7 I. Yamada, H. Fujii, A. Takamatsu, H. Ikeno, K. Wada, H. Tsukasaki, S. Kawaguchi, S. Mori and S. Yagi, Adv. Mater., 2017, 29, 1603004.

8 B. Y. Xia, Y. Yan, N. Li, H. B. Wu, X. W. Lou and X. Wang, Nat. Energy, 2016, 1, 15006.

9 J. Masa, W. Xia, M. Muhler and W. Schuhmann, Angew. Chem., Int. Ed., 2015, 54, 10102-10120.

10 D. Guo, R. Shibuya, C. Akiba, S. Saji, T. Kondo and J. Nakamural, Science, 2016, 351, 361-365.

11 W. Ding, Z. Wei, S. Chen, X. Qi, T. Yang, J. Hu, D. Wang, L. J. Wan, S. F. Alvi and L. Li, Angew. Chem., Int. Ed., 2013, 52, 11755-11759.

12 H. Tang, Y. Zeng, D. Liu, D. Qu, J. Luo, K. Binnemans, D. E. De Vos, J. Fransaer, D. Qu and S. G. Sun, Nano Energy, 2016, 26, 131-138.

13 J. Wang, W. Cui, Q. Liu, Z. Xing, A. M. Asiri and X. Sun, Adv. Mater., 2016, 28, 215-230.

14 X. Zou, X. Huang, A. Goswami, R. Silva, B. R. Sathe, E. Milmekova and T. Asefa, Angew. Chem., 2014, 126, 44614465.

15 S. Gao, Y. Lin, X. Jiao, Y. Sun, Q. Luo, W. Zhang, D. Li, J. Yang and Y. Xie, Nature, 2016, 529, 68-71.

16 S. Li, C. Cheng, X. Zhao, J. Schmidt and A. Thomas, Angew. Chem., Int. Ed., 2018, 57, 1856-1862.

17 Z. Wang, S. Xiao, Z. Zhu, X. Long, X. Zheng, X. Lu and S. Yang, ACS Appl. Mater. Interfaces, 2015, 7, 4048-4055.

18 D. S. Geng, Y. Chen, Y. G. Chen, Y. L. Li, R. Y. Li, X. L. Sun, S. Y. Ye and S. Knights, Energy Environ. Sci., 2011, 4, 760-764.

19 G. Wu, K. L. More, C. M. Johnston and P. Zelenay, Science, 2011, 332, 443-447.

20 M. Li, T. Liu, X. Bo, M. Zhou, L. Guo and S. Guo, Nano Energy, 2017, 33, 221-228.

21 H. W. Liang, W. Wei, Z. S. Wu, X. Feng and K. Mullen, J. Am. Chem. Soc., 2013, 135, 16002-16005.

22 M. Lefèvre, E. Proietti, F. Jaouen and J. P. Dodelet, Science, 2009, 324, 71-74.

23 Y. J. Sa, D. J. Seo, J. Woo, J. T. Lim, J. Y. Cheon, S. Y. Yang, J. M. Lee, D. Kang, T. J. Shin, H. S. Shin, H. Y. Jeong, C. S. Kim, M. G. Kim, T. Y. Kim and S. H. Joo, J. Am. Chem. Soc., 2016, 138, 15046-15056.

24 C. Burda, X. B. Chen, R. Narayanan and M. A. El-Sayed, Chem. Rev., 2005, 105, 1025-1102.

25 J. Wang, H. Wu, D. Gao, S. Miao, G. Wang and X. Bao, Nano Energy, 2015, 13, 387-396.

26 X. Han, X. Wu, C. Zhong, Y. Deng, N. Zhao and W. Hu, Nano Energy, 2017, 31, 541-550. 